\title{
The Emergence of the ERP Software Market between Product Innovation and Market Shaping
}

\author{
Burak Erkut 1,2 (iD \\ 1 Faculty of Business and Economics, Technische Universität Dresden, 01062 Dresden, Germany; \\ burak.erkut@tu-dresden.de \\ 2 Institute for Research in Economic and Fiscal Issues (IREF), 75017 Paris, France
}

Received: 8 April 2018; Accepted: 2 June 2018; Published: 25 June 2018

\begin{abstract}
In this empirical research, the author focuses on the enterprise resource planning (ERP) software market. Based on a contingent perspective of how markets emerge and can be shaped, the author asks the research question of whether the emergence of the ERP market was a necessary, strong, or weak consequence of the product innovation of Systems, Applications \& Products in Data Processing (SAP), which was the pioneer innovator in this specific market. This question is answered with a graph theoretical model of contingency and causality in order to measure the causality between events occurring over historical time. In this sense, the research article provides an application of the method proposed by Lehmann-Waffenschmidt. The author finds that the emergence of the ERP software market is contingent and was not predetermined; path dependencies play a big role in the way how this market segment emerged. With respect to both entrepreneurial and economic factors of relevance, the case of the SAP is far from a predetermined success story. The results are relevant for a number of reasons. First, the results indicate that instead of talking about success stories, a new perspective in market shaping can highlight a more realistic way of the contingent nature of entrepreneurial activity and product innovations. Second, the results aim to bridge the gap between marketing and the emergence of markets, as it was indicated as a research gap by recent contributions in marketing science. Third, the introduction of counterfactual events in the business history of SAP indicate a methodological innovation that has not yet been considered by marketing and entrepreneurship scholars, which may be helpful regarding recognizing patterns from the past and also regarding contingent planning for the future.
\end{abstract}

Keywords: ERP market; product innovation; contingency; market shaping; spin-off

\section{Introduction}

The evolution of a new market is an interesting phenomenon from the perspective of economics, because it reflects how intended human action may have unintended consequences, leading to a dilemma very often discussed, but never finalized by the discipline of economics [1]: On one hand, economic policies aim to provide suitable conditions and incentives for the emergence of new markets; on the other hand, the process of market emergence itself is a gradually self-organized, partially open-loop system characterized with the emergence of novelties.

This dilemma is not only reflected in the theoretical literature [1], but also in the discussion on the relationship between economic freedom and entrepreneurial activity on the national level, where the factors of influence boil down to the infrastructural-institutional factors and factors associated with the activities of individuals on market shaping [2,3]. In fact, the latter factor may also influence marketing science by providing new insights from the early phases of market emergence. A new stream of research questioned the relationship between markets and the marketing literature, and proposed to focus on the emergence of markets in order to gain new insights related for theory and practice [4]. 
These new insights can provide the behavioral foundations of market shaping by focusing on how the market actors make use of the strategies "market driving" and "market driven" [5], possibly in a combination, to generate novelties related for the market and to conceptualize these novelties in a business framework in order to shape a new market segment [6].

The author's aim is to focus on market emergence in the special case of how today's ERP software market emerged based on a product innovation. The question of research is whether the way this new market segment emerged was predetermined, or if the emergence was influenced by contingent events, which would have ended up differently than the factual emergence (meaning that to a given, realized event at a point in time, an alternative event could have been possible, which would have changed the course of the following events). This research question is motivated by the above mentioned dilemma from the perspective of evolutionary economics that the intended market actions of individuals are bounded by contingent circumstances, giving the market a contingent character [6-10]. Based on these considerations, the author provides a review of the literature in Section 2. Section 3 focuses on the methods that will be used to operationalize the research question, whereas Section 4 shows the results of the conducted analysis. Section 5 provides a discussion of the results based on the literature and under the consideration of limitations before it provides a conclusion.

\section{Literature}

In self-organized systems, such as market processes, discovery of new knowledge can be associated with either situational knowledge or technological knowledge. Whereas situational knowledge is associated with the market enabling an individual to act in a certain way in a particular time and place, technological knowledge is associated with economically relevant knowledge such as products, processes, resources or business practices [11]. Competition as a discovery process is associated with the perceptions of individuals and their cognitive abilities, with which they can perceive their environment in different ways, and act upon their perceptions by generating new knowledge relevant for the market [6]. Since individual perceptions differ from each other, and are subjective in their nature, this process is necessarily a subjective one, where every individual possesses a part of the dispersed knowledge relevant for the market, and can turn this particular knowledge into his or her competitive advantage.

As a result of these ongoing attempts of individuals to build competitive advantages based on their subjective knowledge, "markets are always in the making; $(. .$.$) they are the continuous results$ of market practices" [12]. The continuing evolution of markets, and market practices shaping the market evolution in different ways, build the domains of evolutionary economics. This discipline lacks a common ground of analysis [13], and different streams of research give contradictory explanations to questions associated with market evolution, and evolution of new knowledge shaping the market. This discipline of research became popularized by the approach of Nelson and Winter [14], who made a contribution focusing the role of organizational routines in technological competition of innovation and imitation, where routines in organizations build economic analogies of genes in living organisms.

A stream of research within evolutionary economics proposes a way of universal Darwinism that isolates the abstract principles of variation, selection and retention. This stream of research and its supporters claim to provide an explanation to the evolution of any complex system [15]. This approach can be problematic for the case of evolutionary economics, since no proof is delivered so far that a blind analogy building from evolutionary biology would be sufficient to explain economic phenomena, and any approach to find an equivalent of variation, selection and inheritance can also lead to dubious findings, as Levit et al. put forward [16]: “The interpretation of reality can be seriously biased by selectively recognizing only those elements that seem to fit the logic of the chosen principles and ignoring all others, or by constructing disciplinary correlates that actually misrepresent the economic conditions." (p. 557). Levit et al. [16] advises the formulation of specific hypotheses on a bottom-down level (instead of the top-down approach of universal Darwinism) in order to explain the efforts of human beings in shaping markets and their practices within the evolution in an economy. 
The authors summarize these efforts "individual and collective learning, experimentation, insight, inventiveness, and the restless motivations driving these human forms of adaptations" [16] (p. 558). This differs, for example, from the point of view of Foxall and Fawn [17] who claim that once a product innovation is useful, the survival and the success is guaranteed, since experimentation is often based on trial-and-error processes.

By focusing on the question of whether there is an evolution in economics, Lehmann-Waffenschmidt [18] states that in order to answer this question, only a combination of neo-Darwinian and Lamarckian approaches can provide a meaningful framework. Whereas the neo-Darwinian approach consists of the variation, selection and retention paradigm (but differs from universal Darwinism by observing economic and biologic evolutions as separate phenomena that are not interconnected), the Lamarckian approach is the paradigm of the environmental adaptation and the inheritance of acquired properties instead of a blind variation [19]. Especially new empirical evidence from evolutionary biology delivers results that the activation of given inheritance information of an organism is dependent on the environmental factors, supporting the Lamarckian argument [18]. Even though the empirical evidence of epigenetics actually having a memory is an important development against a blind neo-Darwinian framework [18], a further issue deserves special attention.

If the aim is to model economic processes in a nonpredetermined way, the variation, selection, retention paradigm may deliver the problem of post hoc ergo propter hoc [20]: This problem is visible in the observation of two sequential events occurring over time, which may not necessarily build a cause-effect relation. Two examples of this phenomenon are the relationship between a product innovation that occurs at time $t_{i}$, and the success of the innovator at time $t_{i+n}$, and the emergence of a "mother" firm at time $t_{i}$, and the successful emergence of a spin-off ("child" firm) out of this "mother" firm at time $t_{i+n}$.

Especially the focus on entrepreneurial personalities, and stylized ways of representing entrepreneurial processes of knowledge generation and introduction to the market led to an increased focus on the so called success stories [21]. This stylization of "success stories" has also something to do with the game-changing nature of technological innovations. Christensen [22] states that these innovations offer solutions which were previously considered as impossible to be offered; therefore, it is plausible to conclude that this shock effect strengthens the stylization of "success stories". In addition, the fact that entrepreneurship studies mainly focused on positive sides of entrepreneurial personalities neglected its downsides and contributed vastly to the stylization process [21]. Hence, these observations boil down to the example of Lehmann-Waffenschmidt [20] that primarily in case of product innovations and the success of the innovators of these product innovations, the post hoc ergo propter hoc case may be visible.

In case of evolutionary economics, knowledge transfers between firms and markets and the role of spin-offs seem to be an attractive field of applied research [23]. Even though the analogy of inheritance in biology can be built for inheriting organizational characteristics in spin-off formation process, Buenstorf [23] points out that this inheritance process of organizational characteristics may differ from the way biological inheritance occurring across generations: Especially the fact that spin-off founders may influence the way their new organization's routines emerge is a clear distinction from evolutionary biology. The author suggests that a blind analogy building from evolutionary biology is insufficient for explaining the market evolution, suggesting a more bottom-up approach of focusing on the empirical evidence in specific industry contexts.

These observations boil down to the issue that a fresh look on the relationship between product innovation and market shaping is necessary, so that the post hoc ergo propter hoc problem can be solved, and the factors of influence on the transformation process from product innovation to market shaping can be identified-not only those factors that can be classified as enablers, but also those that can be classified as impediments. The relations of causality and analyzing these relations can therefore deliver new insights into these processes, and shed light to the shortcomings of evolutionary economics. Like any other human-made process, the relationship between product innovation and 
market shaping is not a straightforward relationship-not only are there contingent environmental factors that influence this process over time, but also the emergence of game-changing technologies that were previously considered as impossible to offer means that both the users of these technologies and their developers are involved in a mutual discovery process regarding the development and the use of such technologies, which takes time [22].

In fact, the more complex and integrated new technologies became, the new product development (NPD) models became fuzzier [6], which are mainly characterized by the fuzzy stages of NPD instead of very sharp stop/go decisions. This fuzziness targeted to integrate both the pre-step of knowledge generation and the increasing uncertainty in the process of NPD [24]. The pre-step of knowledge generation can be also described as the fuzzy front end of the innovation process, which comprises "those activities that take place prior to the formal, well-structured New Product and Process Development" [24] and is important in order to capture the perceptions of high-profit ideas prior to focusing on NPD. What happens prior to the NPD process is largely tacit; nevertheless, this is the beginning of any evolutionary economic model [6], since the relevant issue in any evolutionary economic model shall be how an economic actor builds knowledge upon the information he or she possesses [25]. The process necessarily involves human mind and its perception of its surroundings. This is done by means of perception-action cycles, where sensory inputs are transformed into tacit knowledge by means of means of a pattern recognition occurring in human mind, and the pattern recognition is based on the unique past experiences of that particular human being $[6,9,10,26,27]$. In Erkut's [6] framework, this tacit knowledge generation process is expressed in terms of a nano dimension which precedes the introduction of the novelty to the market (the micro dimension). This framework integrates, furthermore, the neglected dimension of imagination and leadership in terms of business conceptions $[28,29]$ into the framework of analysis within the meso dimension. Hence, the introduction of the novel idea to the market does not consist of the idea itself, but is associated with how the novel idea is institutionalized in terms of a business conception (described by Witt [28] as an entrepreneurial input), and how a common cognitive framework is created for the members of the firm to proceed and frame the market. The observable competition is on the level of the artefacts, which correspond to the macro dimension; this is not the place where the model stops, but it rather goes back to the perceptions-since also current competition influences the perceptions of market actors, and builds upon their previous experiences. Through that way, an evolutionary process of product innovation and market shaping is observable.

This evolutionary economic perspective on product innovation and market shaping is the first model of evolutionary economics integrating marketing knowledge, product innovation and perceptions of actors into one. The process that smoothly proceeds from the perceptions by means of translating information into knowledge to the generation of a technological artefact is an ideal-typical one of a successful product innovation and the market acceptance. Nevertheless, the author points out to the fact that this is by no means a predetermined process; it is rather contingent due to the contingent nature of knowledge generation, which is central for both business conceptions and market activities $[6,9,10]$.

\section{Methods}

Previous research points to the suitability of the graph theoretical conceptions, especially of the directed graph theory, for analyzing innovations. The suitability of this approach can be explained by means of three advantages [30]: Enabling the modelling of complex structures that cannot be described verbally, quantifying distance between different events over time, and enabling to draw conclusions regarding structural similarities of evolving economies.

In the context of the author, the point of departure is the question-whether the success of a pioneer firm offering a product innovation is a necessary, or a weak, or a strong consequence of the product innovation. An event is called as contingent, when it is "not impossible, but not necessary" [31]: If the present state does not have any alternatives conceivable from the past state(s), the present state 
can be observed as being the necessary consequence from the past. However, this is not always the case, especially when complex processes in the real world are taken into account, indicating that the present state is contingent. A product innovation is associated with new technological knowledge, hence, it goes back to "the cognitive structure underlying possible developments in industrial activities" [30] and like in any other process involving human decision making, also the cognitive structures involving product innovations and market shaping activities based on these product innovations are contingent, since they involve the transformation of (objectively available) information to (subjectively generated) knowledge $[6,9,10,25]$, and the conceptualization of this particular bit of subjective knowledge in terms of a business idea $[28,29]$. These considerations can be operationalized and quantified in a graph theoretical context in order to answer the question of interest.

Once a contingent event $E_{i}$ at time $t$ is taken into account, a timeline of contingent events can be formalized by graph theory. The method suggested by Lehmann-Waffenschmidt [31] defines a contingent event $E_{i}$ at time $t$ to be "an element of an appropriate set of alternative possible events at this point in time" [31]. Connecting one contingent event to the next over (continuous or discrete) time can generate a time directed contingency graph, which visualizes an evolving process based on the time path of the contingent events, where a state of a time path is called to be contingent when it has at least one possible successor of the previous event in time. In this context, an evolving process is a path, i.e., a sequence of states with start at $t_{i}$ and end at $t_{i+n}$ in case of a finite sequence of states. A state of $E_{i}$ is contingent in the prograde sense, "if besides $E_{i+1}$ there is at least one more state at time $t_{i+1}(\ldots)$ which is a possible successor of $\mathrm{E}_{\mathrm{i}}$ " [31] in the contingency graph and the m-prograde alternative set includes all possible states of the given contingency graph at time $t_{i+m}$, which may be reached from the state $E_{i}$ in the given contingency graph, $m>0$ [31].

Since contingent means having at least one alternative possible event at the given point in time, in addition to the realized time path, the alternative possible time paths need to be constructed. This can be done by counterfactuals for the sake of analyzing and understanding causality relations between past states and the present state. However, such a counterfactual analysis faces the questions of how the counterfactuals will be selected, and which counterfactuals can be considered as relevant. An identification of counterfactuals can be done, in which factual alternatives to the process of interest are considered as comparative counterfactual processes [31]. Counterfactuals, or factual alternatives, can be structurally similar processes [1]. With structural similarities, the focus is on certain properties of two or more processes that reflect a resemblance in the defined properties, even though they may differ in other properties that are not relevant for the analysis. These processes either occur in synchronic or consecutive time, and were generated either by a system itself or by decision-makers [31].

Throughout the analysis, an event $\mathrm{E}_{\mathrm{i}}$ without a superindex indicates the realized event $\mathrm{E}$ at point of time $i$ from the path of the realized process of events. On the other hand, an event $E_{i+1}{ }_{1}^{I, I I I I I I, I V}$ at point of time $i+1$ indicates a counterfactual event $E$ at point of time $i+1$ which is permissible and possible, constituting a common event of the processes I, II, III and IV, which will later evolve into distinctive processes (that may or may not converge over time), but nevertheless share at least one common point in the past, namely at point i.

Even though in the strict sense, causality is "a close relation between observable causes and consequences" [31], the graph theoretical approach defines causality as "the gradually measurable intertemporal relationship of any two states of the evolution of observable characteristics ( ... ) of the evolving system under consideration" [31]. Provided that in a given contingency graph there is at least one path which connects two arbitrarily chosen states $E_{i}$ and $E_{i+n}$ where $n>0$, the prograde degree of causality [31] can be calculated by putting the number of all connecting paths between the event of $E_{i}$ and the event of $E_{i+n}$ into relation with the number of all alternatively possible paths between the event $E_{i}$ and any event at time $t_{i+n}$. The meaning of the prograde degree of causality can be expressed as asking whether the state $E_{i}$ is a necessary, or a weak, or a strong cause for the state $E_{i+n}$, or alternatively, whether $E_{i+n}$ is a weak or a strong consequence of its precursor $E_{i}$ [31]. Prograde causality is measured between 0 and 1; 0 indicates that there is no causality between the two events; 1 indicates that there is 
a determination, hence no other alternatively possible paths exist. The closer the calculated number to 1 , the stronger the causality in this context.

\section{Results}

\subsection{Data and Market Context}

This section aims to present an analytical model of the evolution of SAP's (Systemanalyse und Produktentwicklung in German, or, Systems, Applications \& Products in Data Processing in English) product innovation " $R$ " and the way it shaped the market over irreversible historical time. In 1972, SAP introduced a software program to the market which was targeted to businesses. This software program was the first one standardized for businesses, integrating business processes for sales, materials management and accounting and allowing to enter data in real time [32]. The latter property corresponds to today's terminology of "online", and was associated with the product name " $R$ " for real time. By providing this software, SAP changed decision making processes in businesses by reducing transaction and agency costs, and making use of network externalities in form of standardization [33]. This product innovation is accepted as the starting point of a new market segment, that is, in today's terminology the market for enterprise resource planning (ERP) software [33]. As found out by Yun et al. [34], how a certain market is shaped depends much on the leading firms' behavior; hence, the focus on SAP as the global market leader for the ERP software market can deliver new evidence for exploring and explaining the complex relation between product innovation and market shaping.

Based on the above-mentioned method, the author translates the research question into the context of the causality measurement due to Lehmann-Waffenschmidt [31] as follows: Was SAP's success a necessary, or a strong, or a weak consequence of its product innovation? To be more precise, the author asks whether we can explain SAP's market shaping success with the variation-selection-retention paradigm and by constructing a blind analogy from evolutionary biology, as suggested by the universal Darwinian framework $[15,19]$ and the corresponding image of the heroic innovator [35], or if the market expansion process of its product innovation is rather a contingent process [6]. Here, the author expects that SAP's market success is not a necessary consequence of its product innovation, hypothesizing Hayek's [7] observation that the evolution of the market has a game-like structure where both luck and plans of actors are relevant for the direction of the evolution.

By trying to answer this question with universal Darwinian arguments, one may choose a wrong turn for explanation, since these arguments may fall into the trap of post hoc ergo propter hoc [20]. The same applies for (neo-)Schumpeterian traditions of observing either entrepreneurs without firms, or firms and routines without entrepreneurs [36]. These different (neo-)Schumpeterian models seem to neglect an important dimension of the market process; imagination, leadership and the entrepreneurial input focusing on business conceptions [28]. A further shortcoming of the neo-Schumpeterian scope of research is to take a dualistic ontological stance on the relation between change in nature and change in economy [37]. This seems to be a problematic view, since knowledge generation relevant for economic change starts in the human mind $[6,9,10,27]$ and through the involvement of human cognition, an interdependency between economy and nature can be established, as the latest attempts to associate the psychologic work of Hayek with his economic theories also demonstrate $[6,10,38]$.

The first step of the analysis was to identify the success factors of SAP's product innovation based on the literature [33,39-43]. Table 1 summarizes and categorizes the literature review conducted by Erkut [33] regarding the success factors of SAP, where $\boldsymbol{V}$ indicates a direct implication of the corresponding contribution regarding a certain success factor, $(\boldsymbol{V})$ on the other hand indicating an indirect implication that is interpreted by the author as belonging to the certain success factor. The "compatibility with IBM (International Business Machines Corporation)" factor indicates that SAP's software program was compatible with IBM mainframe computers [41]. With "word-of-mouth strategy", the author indicates the marketing strategy used by SAP in order to market its product 
innovation " $\mathrm{R}$ " and its successors [32], which was mainly by focusing on managers of firms that were potential customers of SAP, instead of a direct marketing campaign.

Table 1. Success factors of SAP's "R" in the literature.

\begin{tabular}{|c|c|c|c|c|c|}
\hline $\begin{array}{ll}\text { Contribution } \\
\text { Success Factor }\end{array}$ & [39] & [40] & [41] & [42] & [43] \\
\hline Product Innovation & $\boldsymbol{\nu}$ & $\boldsymbol{\nu}$ & $\checkmark$ & $\checkmark$ & $\boldsymbol{V}$ \\
\hline Compatibility with IBM & $\checkmark$ & $\checkmark$ & $\checkmark$ & & \\
\hline Word-of-Mouth Strategy & & $\checkmark$ & $\checkmark$ & $\checkmark$ & \\
\hline International Focus & $(\boldsymbol{V})$ & $(\boldsymbol{V})$ & $\checkmark$ & & \\
\hline Cocreation with Customers & & & $\checkmark$ & $(\boldsymbol{V})$ & $\checkmark$ \\
\hline Organizational Structure & & & $\checkmark$ & $\checkmark$ & $(\boldsymbol{V})$ \\
\hline
\end{tabular}

Source: Based on [33]. $\boldsymbol{V}$ : Direct implication as a success factor, $(\boldsymbol{V})$ : indirect implication as a success factor.

It has been questioned by Tuomi [35] whether the notion of a "success story" has a good explanatory power when it comes to innovations and their success in the market. Taking a look at the relevant success factors that were identified in the literature, it can be questioned whether these properties that constituted the success of SAP had any plausible alternatives that would hinder its success in shaping a new market segment. From this perspective, the focus will be put on the emergence phase of SAP in order to take a look at other firms in the software market which emerged during this era. SAP was one of a handful of software firms that emerged in West Germany after the unbundling decision of IBM [41]. The software-oriented firms that emerged during this era can be categorized with three different organizational structures; software firms, consulting firms and hybrid firms combining software development and consulting [41].

The emergence of West German software market after the unbundling decision of IBM and the successful product innovation of SAP were both key events in the evolution of the global ERP market. SAP's product innovation was an answer to the long lasting debate on standardization versus adaptation [40], which emerged during the 1970s as a challenge for multinational corporations to balance the trade-off between increased needs of global integration in terms of competing standards, and local adaptability and responsiveness. This was a challenge for the transformation towards electronic data processing and information-based decision-making systems in firms, since on the one hand a cross-functionality was recognized as a need to enable better and more precise decision-making processes for the management level. On the other hand, local adaptability and responsiveness implied that such a cross-functionally integrated software program meant excessive planning and lack of flexibility [40]. Hence, two alternative standards on the market emerged as the integrated business software program R of SAP, and diverse single-function software programs from different software vendors.

Based on the literature on lead users [44], it can be asked whether a tendency for own development of the software should be expected, i.e., whether a fourth category of lead user firms can be added to the three categories mentioned above. Empirically, the closest form of a firm to that of lead users was university spin-offs, but in case of SAP, this is questionable, since the software program $\mathrm{R}$ was developed together with an industrial customer. According to Leimbach [41], such a tendency for own development was associated with very difficult market conditions of standardized software applications. In addition, industrial users were for software firms both potential customers and potential competitors regarding the market for qualified employees [41]. These considerations, together with the lack of software firms and the lack of knowledge in case of industrial users led to the fact that a phenomenon like lead users did not emerge in 1970s Germany in the case of standardized business software integrating business processes in real-time. Hence, lead user firms or university spin-offs cannot be considered as a fourth category. 
The evolution of different types of IBM spin-offs goes back to the decision of unbundling hardware from software by IBM, which is generally accepted as the starting point of the software market in the USA (United States of America) [45] and had similar effects in Europe, especially in West Germany [41]. Many former IBM employees resigned to establish their own firms, and the emergence of software firms of West Germany in this era can be associated with a number of IBM spin-offs, as well as some subsidiaries of other foreign firms and university spin-offs. In terms of Buenstorf [46], IBM served in this context as an enabler of a number of spin-offs that emerged. Since IBM played a big role during this emergence process, and its concentration on hardware turned out to be less promising as it was considered initially by the management level [41], a relevant question would be whether the unbundling decision was an inevitable one for IBM. For considering this, taking a look at IBM's competitor Apple would be relevant in order to see what makes the unbundling decision of IBM unique in comparison to Apple's strategy of not to unbundle hardware from software.

Unlike IBM, the US Department of Justice did not put pressure on Apple to unbundle hardware from software, simply because it was serving a niche market where most of its profit was coming from hardware [47]. Hence, not only seems the unbundling decision to be inevitable for IBM, but it is also visible why the US Department of Justice put pressure on IBM and not on Apple regarding the implementation of the unbundling strategy. Hence, it was inevitable for the German computer industry to observe the birth of a number of software firms after the unbundling decision of IBM. Clearly, these IBM spin-offs noticed some profit opportunities outside IBM, which they could exploit, a characteristic of opportunity-induced spin-offs [48], but there were also some spin-off founders who simply did not see any favorable conditions in IBM to continue to their careers, a characteristic of necessity-induced spin-offs [48].

Even though the motivations of the entrepreneurs may be different, the institutionalization of a new idea goes beyond the type of the spin-off to a cognitive dimension of organizing economic resources, which Witt [28] names as "business conceptions". According to Witt [29], a business conception consists of "subjective, sometimes highly idiosyncratic imaginings in the mind of (potential) entrepreneurs of what business is to be created, and how to do it" (p. 1127). Due to its subjective nature, a business conception has a contingent nature, and how a business conception emerges is not only dependent on the (potential) entrepreneur's cognitive dimension, but also how this cognitive dimension generates a pattern of association at a certain time with previous experiences of that particular person that resemble the current experience at that certain point of time [6,9]. As Witt [29] puts forward, this process of pattern recognition and knowledge generation regarding the business conception of the (potential) firm is guided by cognitive frames of (potential) entrepreneurs, which are very subjective and heterogeneous, leading to the formation of different business conceptions due to different framing and selection effects regarding the interpretation of perceived information associated with the business conception.

\subsection{The Factual Process}

The factual process starts in February 1972 with the recognition of the objectively available information by Dietmar Hopp and Hasso Plattner and their cognitive capability to transfer this objectively available information into tacit and subjective knowledge-i.e., the nano dimension described by Erkut [6] $\left(E_{i}\right)$. In this context, this corresponds to the higher order opportunity [49] of the need for an integrated business software program working in real time, and standardized for firms. By recognizing this higher order opportunity which existed in an objective way [49], the two engineers came together with three other personalities Klaus Tschira, Hans-Werner Hector and Dr. Claus Wellenreuther to become a team for turning this tacit knowledge into a new product with a corresponding business conception [28]. SAP was established in April 1972 as a software firm with flat hierarchies, where all cofounders contributed to the transmission of tacit knowledge into a software program $\left(E_{i+1}\right)$. What the cofounders had in common was their previous employment in IBM, and how they resigned from IBM in order to develop their idea (where Dr. Wellenreuther resigned from 
IBM before Hopp, Plattner, Hector and Tschira). Nevertheless, the newly founded SAP did not have any investors and did not own any computers to work with, therefore, after some time in coding in the newly founded headquarters, around May 1972 it started the initial phase of the NPD. It could only focus on the NPD in codevelopment with its customer ICI $\left(\mathrm{E}_{\mathrm{i}+2}\right)$, by using the computer facilities of ICI $[32,41]$. At the beginning, the NPD consisted for only the use of ICI, but nevertheless, the cofounders made a deal with ICI enabling the further sale of the software program upon a successful NPD. Hence, around the same time as the first efforts were done by cofounders, SAP cofounders contacted the managers of firms which were operating in the Rhine-Neckar Metropolitan Region (RNMR) to inform them about the advantages of the software program which they were developing. As shown by Erkut [33], the software program $R$ shaped the market later on by means of making use of network externalities, and by reducing agency and transaction costs.

The fact that the cofounders recognized similar business processes and similar needs regarding business software in different firms during their employment period in IBM also means that they continued to make use of their previous customer network. Since RNMR was a plethora of industrial firms-both German firms competing internationally, and foreign firms with branches in RNMR-it was for SAP's advantage to show these potential customers the ways they were codeveloping the program with ICI [32] in the early months of 1973. Through that way, it aimed to perform regional market shaping by focusing on the needs of the potential customers, but building a new product to address these needs $\left(\mathrm{E}_{\mathrm{i}+3}\right)$ [5]. In addition, SAP cofounders got the help of Kurt Bruch, a consultant who previously did his PhD at the chair of Walter Georg Waffenschmidt in Heidelberg University right before Claus Wellenreuther, in order to reach the managers of firms active in RNMR. Through this way, not only did SAP try to optimize the standardization process of the software program, but also made sure that there would be a market demand. Therefore, the marketing strategy chosen was a word-of-mouth strategy $\left(E_{i+4}\right)$, where the point of time corresponds roughly to June-August 1973 since Kurt Bruch was holding meetings with the managers in his consulting firm during this time, where SAP cofounders were already talking on the first version of the prototype. Nevertheless, these meetings were formalized and gained importance in 1974, since the product was officially available for sale around that time. This strategy was used by SAP for more than two decades to reach the target group of managers [32].

In the starting phase, there were also manager launches at ICI (Imperial Chemical Industries) where potential SAP customers were observing the progress of the NPD. Since these potential customers were either foreign firms with branches in RNMR, or German firms of RNMR with branches in foreign countries, an international focus emerged around this time in the cognitive organizational framework of the newly established SAP $\left(E_{i+5}\right)$, roughly corresponding to the late months of 1973 . As it would be seen later on, the way SAP shaped the global software market was mainly due to this early internationalization focus by the interactions with internationally oriented industrial customers.

The successful NPD was finalized in December $1973\left(E_{i+6}\right)$ and was a result of the codevelopment with ICI, especially the key feature in the successful development was to make use of ICI's IBM mainframe computer of type /360 in order to simulate higher hardware capacities of the future IBM mainframe computer of type /370 - in other words, the cofounders went beyond the restrictions of the technological frontiers [32] in order to continue with their product innovation. The cofounders made use of the word-of-mouth strategy to emphasize the market shaping effects of their software program. This ended in the success of $\mathrm{R}$ in the market, creating a new product class and differing from both the rest of the software programs that were available $\left(E_{i+7}\right)$ in the market conditions of 1974 . Especially since until that time business processes of firms were organized in terms of data collection and data processing by different groups in teams, firm managers targeted to cut costs by investing in $\mathrm{R}$, since the integration of different business processes into a single software program meant that not every department of a business would need a different team for data processing [32]. Furthermore, the fact that the same information would have to be processed each time at different departments of a business until the introduction of $\mathrm{R}$ also meant that through that way both costs and the risk of 
wrongly entered information would be reduced [33]. The question at this point is, whether this was a necessary consequence of the new technological knowledge that was building the basis of SAP's product innovation. For this purpose, the author considers three different counterfactuals.

\subsection{Counterfactual 1: SAP as IBM's Subsidiary}

The author considers SAP being IBM's subsidiary $\left(\mathrm{E}_{\mathrm{i}+1} \mathrm{I}_{\mathrm{II}, \mathrm{III}, \mathrm{IV}}\right)$ as a plausible alternative development that could have occurred, but did not. In addition to the fact that IBM subsidiaries existed in other forms throughout its business history (hence, corresponding to an alternative factual occurring in consecutive time), the plausibility can be expressed in terms of the following factors: First, the key role Dr. Claus Wellenreuther had in IBM Germany, who was not considered during the centralization process of software development, which led to his resign and the key role he took in SAP's founding team. In addition to being the only one with a business degree in the founding team, he was known in the home region of IBM Germany and SAP with the "Wellenreuther bookkeeping" software methods, which contributed to the word-of-mouth strategy of IBM Germany and SAP [32,41]. In addition to that, the state of the art technology to capture business processes prior to the establishment of SAP was causing problems in data processing of firms [33], which implies the emergence of a higher-order opportunity in terms of Buenstorf [49], meaning that there was an opportunity to create an opportunity. One such attempt was IBM Germany's codevelopment of a real-time data processing system with an industrial client called ICI in order to solve this problem. This attempt ended up as an IBM working paper, and ICI requested IBM Germany to continue with the development of the software program with Hasso Plattner and Dietmar Hopp (later on, two of the founders of SAP), which was rejected by IBM Headquarters in Germany [32] upon the regret of IBM Germany head Henkel after the emergence of SAP [50]. The integration of single-function systems into one-one of the most important properties constituting the product innovation that shaped the market-was already an attempt by IBM in its COPICS concept [32].

Therefore, there are plausible reasons for considering SAP as an IBM subsidiary. The question is, whether this organizational form occurred at any point of time in IBM's history-and what it would have looked like. The suggestion of ICI to IBM Germany was to codevelop the software program together with Plattner and Hopp independently from the central software development unit of IBM Germany in Stuttgart $\left(E_{i+2}{ }^{I, I I, I I I, I V}\right)$, which is structurally similar [1] to the IBM USA's "Project Chess" [22,51] in 1980, which was an independent development unit for personal computers far away from IBM's Headquarters in New York. This alternative factual case is therefore a case in consecutive time and generated by decision makers [31]. Whereas the time limit for "Project Chess" was one year [51], SAP's factual start-up phase and the real standardization phase of the program took up to 10 to 15 years according to Dietmar Hopp [52]. This was basically because the target was to create a standardized software program that would capture the business processes of any industrial firm [32]. Even though the idea went back to recognizing patterns in business processes of different firms, fitting this in a software program was very challenging. This would have taken time and placed enormous pressure on the developers $\left(\mathrm{E}_{\mathrm{i}+3} \mathrm{I}, \mathrm{II}, \mathrm{III}, \mathrm{IV}\right)$. One of the most important reasons that caused a factual delay is the technological frontiers of the era-the technological frontiers were IBM's mainframe computer of type/360 and the display terminals of IBM 2260 [32], and they were not able to function with SAP's software. Only after writing a special software program to simulate larger hardware capabilities, the cofounders of SAP succeeded to have a compatible software program. Whereas going beyond the technological frontiers was only with the imagination of cofounders possible, this also means that the imagining of not existing technological alternatives would not have necessarily occurred in any other case. The author points out to a number of previous attempts that were unsuccessful because of the restrictions of technology frontiers [41].

Since one of the reasons of the factual rejection of IBM Germany was that it was too costly for it to keep two of its good employees for a single customer [32,41], and due to IBM Germany's own dependency on IBM USA, the author concludes that the headquarters of IBM in USA would have 
decided on the continuation of this codevelopment project. This conclusion is also in line with the factual development of IBM Germany after the resignation of the SAP cofounders, as it was written by Henkel, whose suggestion to concentrate on the opportunities regarding material resource planning software was rejected from the headquarters in USA, which corresponds to today's ERP software. It is clear that the focus of IBM USA was on hardware [41,50].

An acceptance of the continuation of the project from IBM USA $\left(\mathrm{E}_{\mathrm{i}+4}, \mathrm{I}, \mathrm{II}, \mathrm{III}\right)$ can be considered as plausible because of a number of reasons: The first written evidence of the blueprint of SAP's " $\mathrm{R}$ " was published as an IBM working paper with Plattner, Hopp and ICI manager Meier [41] being the coauthors-implying, even though IBM was focused on hardware, it might have claimed the intellectual property rights of the working paper. In addition, the technological frontiers of business software were causing big problems for the industrial customers of IBM [32], hence, the need for a better alternative was visible. These two reasons may seem contradictory to the hardware-focused strategy of IBM, nevertheless, it must be said that the unbundling strategy of IBM was restricted to a certain level in order to overcome antitrust actions against it and was not a complete sacrifice from software development [53]. In addition, since IBM had a strategic position regarding its hardware systems, development of software that would be priced separately brought a competitive advantage to it [53] due to the fact that new software programs were designed in a compatible way with IBM hardware. In this way, the intervention of the IBM headquarters in USA implies that the decision met would have been done with respect to the relevant target group of the much more developed software market in USA, rather than the emerging one in West Germany. Since IBM's target was to make use of software in order to increase the value of hardware [32], and since a continuation of the NPD would imply higher costs for IBM, it is plausible to consider that IBM USA would evaluate the continuation with the perspective of the software market in the USA. A knowledge filter or a bias as was the real case as IBM Germany's head Henkel suggested the headquarters in USA to start an alternative to SAP [50].

This is contingent on how far the headquarters in USA would overcome the knowledge filter described by Audretsch and Link [54]. According to the authors, the knowledge filter may prevent the process of new knowledge shaping the market. A historical observation by Lehrer and Behnam [40] points out to the fact that the software market in the USA was primarily a market of single-function systems which is the opposite of the standardized software program of SAP that integrated different business processes into one. Hence, if the headquarters would have accepted the continuation of the software development, this acceptance would be based on their ability to identify a market gap [5] in the software market in the USA, implying an emigration of the program to the headquarters. This counterfactual is structurally similar to the alternative factual development that was the case in Software AG [41], which shifted its focus from Germany to USA soon after it was established [55], even though it has its headquarters still in Germany. The reason behind this shift was that the need for its products was more visible in the (more developed software market of) USA than in Germany. Hence, an emigration to the headquarters $\left(E_{i+5}{ }^{\mathrm{I}, \mathrm{II}, \mathrm{III}}\right)$ is a plausible counterfactual.

What would the continuation of the NPD look like, if it would have been done in the IBM USA? Since the factual development of the software was long, a structurally similar alternative factual NPD may be considered as a counterfactual event. A factual NPD during this era within IBM USA was the development of the Future System project. This project was a megaproject involving a radical development of a product line to incorporate technological developments within the IBM framework, starting in 1971 and ending in 1975 [56]. According to Thürmer [56], both conformism of an IBM egocentrism and risk aversion influenced the decision of the IBM Management Committee to stop the development of this project in 1975. This was due to the factual reasons behind the crisis in IBM, which led to the end of the Future System project, i.e., the lack of decision-making ability of the management level in order to match the firm strategy with the available technological developments [56]. This would have also played a role in the counterfactual NPD of "R" in the USA, since IBM as a whole was affected by these reasons. 
This would have led to three different outcomes:

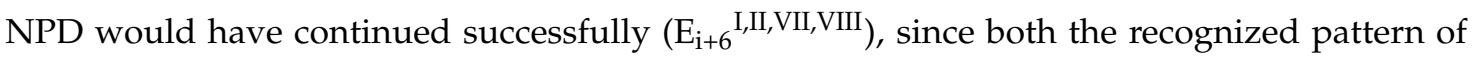
business practices and processes was not specific to West Germany-hence, developers would continue to learn from the interactions with customers, and continue with the standardization. The continuing interaction would have evolved to customers recognizing the need for this software, and willing to invest for it, even though there was a recession $\left(\mathrm{E}_{\mathrm{i}+7}, \mathrm{I}, \mathrm{VII}\right)$. A reason for this would be the failing capabilities of single function systems to reflect the real time state of business processes in an integrated way. Hence, the opportunity costs of staying with the dominant software systems of the era would be too high considering the problems they caused for decision-making and planning on the management level [33]. The successful continuation of NPD can be seen in some parts of the Future System project developed after the official end of this project, becoming successful in the market, such as IBM's System/38 and 3800 laser printer [57].

Alternatively, the successful continuation of NPD would have ended as being an unsuccessful innovation $\left(\mathrm{E}_{\mathrm{i}+7} \mathrm{II}, \mathrm{III}, \mathrm{V}, \mathrm{VIII}, \mathrm{IX}\right)$, as it was unable to reach and influence the target groups. The plausibility of this counterfactual consideration can be explained with the fact that even in 1990s, where SAP's software programs were already successful in Germany, the notion of an integrated software was still hard to grasp in the USA [40]. The knowledge filter [54] was therefore harder to overcome in USA than in West Germany. Therefore, it is plausible to consider that customers might have wanted to stick to single-function systems instead of investing into an integrated system during the Recession. SAP's presence in USA starting in 1988 [32] is an alternative factual in consecutive time for this counterfactual—even though in 1990 SAP was among the top five business software firms, the US market was still underrepresented in terms of its sales; in 1990, it was less than 5\% [45] and only with the third generation of its software, $R / 3$, there was a significant increase.

Finally, the alternative of an unsuccessful NPD can also be considered as a counterfactual event $\left(\mathrm{E}_{\mathrm{i}+6}{ }^{\mathrm{III}} \mathrm{IX}\right)$. The plausibility of this event is explained with the changes IBM was going through during this era. According to Thürmer [56], the reason behind the organizational problems IBM went through was its deviation from its founding principles and the lack of a clear strategy in order to allow for an organizational innovation. This lack of perspective was also visible in IBM Germany, not only in the headquarters, and as Plattner expressed, the founding team of SAP noticed that there wasn't enough freedom to innovate within IBM - these organizational problems and their role in the unsuccessful end of the Future System project, would have also caused an unsuccessful NPD. In addition, the vertically organized structure of IBM and the interventionist policies of the central management committee [56] would have affected the innovative perspectives negatively, leading to the unsuccessful end of the project $\left(E_{i+7} I I, I I I, V, V I I I, I X\right)$, just like in the case of Future Systems.

These three counterfactuals are contingent upon the decision of IBM CEO Cary overcoming the knowledge filter [54] and allowing the development of the software program in IBM USA. As described by Audretsch and Link [54], new technological knowledge which presupposes the products developed out of them are "inherently uncertain" (p.12), and their outcomes or values cannot be forecasted precisely since their development is non-predetermined-a basic notion of what makes a new idea "new". The already failed attempt of IBM Germany's head Henkel to convince the IBM USA headquarters for developing a similar software program can therefore be used in this context as a counterfactual $\left(\mathrm{E}_{\mathrm{i}+4}{ }^{\mathrm{IV}}\right)$, stopping the process.

\subsection{Counterfactual 2: SAP as a Consulting Firm}

The main trend among newly established software-oriented firms was to become consulting firms [41]. This trend is considered as a "driven by the market" strategy [5] since consulting firms were not involved in the development of the software programs but rather focusing on individual (organizational or software-oriented) solutions for their customers [41]. The plausibility of SAP becoming a consulting firm is explained with cofounder Plattner's view that becoming a consulting firm was an option for SAP, since both himself and Hopp were system advisors to IBM customers, 
and were not a part of the software development team of IBM [58]. A strong argument for consulting firms is that almost all software firms established after the unbundling decision of IBM in West Germany were either consulting or hybrid firms combining consulting and software development jointly [41]. In the specific case of SAP, the restricting factor of the technology frontiers not allowing the development of the software program [32] and the associated solution by the cofounders to simulate larger hardware capacities indicate that also SAP might have been ended in the case where the higher order opportunity was perceived by them, but they were not able to develop it $\left(E_{i+1}{ }^{\mathrm{V}}\right)$-since imagination of non-existing alternatives such as simulating nonexistent hardware capacities is very subjective. In addition, as Plattner says, "SAP might not have come into being were it not for his efforts one rainy day in 1972" [59].

Since the initial version of " $R$ " consisted of around 2000 punch cards, which Plattner accidentally dropped onto a wet floor during a rainy day, the continuation of the NPD was only possible because the cards were not completely damaged. If the cards had been completely damaged, it would have been possible that Plattner and the other cofounders would not have been able to completely rewrite the software program in the same way as it was before, and since the opportunity costs of becoming consultants were lower than spending more time for the software program (without a funding source), they would have become consultants.

In a similar way, another (future) ERP vendor started its operation quite differently, but shifted its focus. Larry Elison, Oracle Corporation's cofounder, initially started to focus on IBM's System $\mathrm{R}$, which is a database system and the first application of SQL. Even though his aim was to have a compatible product with IBM's System R, but his efforts were stopped by IBM, which did not agree to provide him some error codes [60]. Instead of continuing his efforts, he changed his focus. Hence, it is plausible to consider that SAP would have shifted its focus from software development to services $\left(\mathrm{E}_{\mathrm{i}+2} \mathrm{~V}\right)$. Since the dominating software form in the market was single-function systems like in the USA, they would have continued to work within the available technological frontiers to focus on individual solutions instead of software development and standardization/integration $\left(\mathrm{E}_{\mathrm{i}+3} \mathrm{~V}\right)$. In this particular setup, the focus of SAP cofounders would turn into the international software market to capture new developments for creating these individual solutions to the customers $\left(E_{i+4}{ }^{V}\right)$. This would have altered the evolution of the ERP market—since around the same time another German hybrid firm, ADV/Orga, was focusing on standardized single-function software programs (IPAS for human resources, IFAS for accounting, ICOS for cost management), the market would have evolved towards the dominance of the standardized single-function software programs instead of an integration $\left(E_{i+5} \mathrm{~V}, \mathrm{VI}\right)$. No NPD would have come into existence $\left(\mathrm{E}_{\mathrm{i}+6} \mathrm{~V}, \mathrm{VI}\right)$ and those that came into existence like from ADV/Orga would have had the character of single-function systems, eliminating the possibility of $\mathrm{R}$ not becoming successful $\left(\mathrm{E}_{\mathrm{i}+7}, \mathrm{II}, \mathrm{III}, \mathrm{V}, \mathrm{VI}, \mathrm{VIII}, \mathrm{IX}\right)$ since the dominant designs in the market would not have the same market shaping effects as R [33]. This corresponds to the factual development of the software market in USA, hence, the counterfactual is an alternative factual occurring in synchronic time.

\subsection{Counterfactual 3: SAP as a Hybrid Firm}

A third type of business conception that is relevant and plausible is the hybrid form $\left(E_{i+1}\right.$ VI,VII,VIII,IX $)$. Among the software oriented firms that emerged during this era, important firms like Softlab were hybrid ones that combined both consulting and software development. Since SAP was not a one-man business but involved five different cofounders with different competencies, the decision of flat hierarchies and equal contribution of all cofounders to software development is not a necessary decision - as it can be seen from the course of the events, one of the cofounders (Hector) was in fond of hierarchical structures, and another one (Wellenreuther) worked with his own group in SAP like a firm within the firm, and later established his own software company [32]. In addition, Hopp and Plattner were system advisors at IBM and not software developers [32], meaning that a division of labor between consulting and software development would have been possible. These facts confirm the plausibility of a hybrid firm, since this type of firm often involves more hierarchical structures that are necessary 
to cope with dual capabilities of software development and consulting. In addition, SAP started its cooperation with consulting companies in 1980s [32] as a result of the need for consulting regarding SAP software, which is also a plausible reason to consider that SAP would have been a hybrid firm.

The hybrid firm would have had a clear division between software development and consulting $\left(\mathrm{E}_{\mathrm{i}+2} \mathrm{VI}, \mathrm{VII}, \mathrm{VIII}, \mathrm{IX}\right)$. This would have implied that the organizational structure would have involved developing dual capabilities for both processes. Among the two branches, software development is more cost-intensive than consulting $\left(\mathrm{E}_{\mathrm{i}+3}{ }^{\mathrm{VI}, \mathrm{VII}, \mathrm{VIII}, \mathrm{IX}}\right)$ - and even though ex post it was visible that SAP's product innovation shaped the market in a very radical way [33], ex ante this was not foreseeable due to the knowledge filter [54]. Hence, due to the convenience of consulting, the unpredictable nature of the product innovation and cost-intensive structure of software development, this branch would

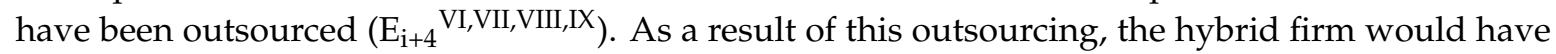
evolved into a consulting firm, focusing on individual solutions instead of software development.

Here, two outcomes would have been possible. First is a focus on the single function software products $\left(\mathrm{E}_{\mathrm{i}+5} \mathrm{~V}, \mathrm{VI}\right)$ as it has been the case described in the counterfactual event of SAP being a consultant firm, leading to a market where standardized single function software products would have been in dominating roles $\left(\mathrm{E}_{\mathrm{i}+6} \mathrm{~V}, \mathrm{VI}\right)$ and the emergence and the diffusion of $\mathrm{R}$ would not have come into existence $\left(E_{i+7}{ }^{I I}, I I I, V, V I, V I I I, I X\right)$. Second is the possibility that the "outsourced" group of software developers would have established an autonomous software firm to provide the necessary software for the hybrid firm which evolved into the software firm. The autonomous software firm would have continued the NPD $\left(\mathrm{E}_{\mathrm{i}+5}{ }^{\mathrm{VI}, \mathrm{VIII}, \mathrm{IX}}\right)$, but the success of the NPD would have not followed straightforward, since the factual process of the NPD in case of SAP involved the joint work of all cofounders who had different competencies relevant for the successful NPD. If this would have been achieved with a part of the cofounder team, and a part of the employees of the original hybrid firm, there would have been a successful NPD ( $E_{i+6}$, II,VII,VIII). The successful NPD would necessarily require the acceptance of the target group and their willingness to invest into the software program. In this case, the consulting firm would have been a catalyzer, but the outcome would have been dependent on the ability of the target group to prefer a standardized and integrated software program to individually developed ones which were single function software programs, hence, implying either success $\left(\mathrm{E}_{\mathrm{i}+7}{ }^{\mathrm{I}, \mathrm{VII}}\right)$ or no success $\left(\mathrm{E}_{\mathrm{i}+7}, \mathrm{II}, \mathrm{III}, \mathrm{V}, \mathrm{VI}, \mathrm{VIII}, \mathrm{IX}\right)$. If the development of the software program with a part of the original cofounder team would have not been achieved successfully ( $E_{i+6}{ }^{I I I I X}$ ), the NPD would be unsuccessful $\left(E_{i+7} I I, I I I, V, V I, V I I I, I X\right)$, and the hybrid firm which evolved into a consulting firm would have been focusing on services and consulting without being affected by the unsuccessful NPD of the outsourced software unit.

The structurally similar alternative factual in this case is the resignation of SAP cofounder Dr. Claus Wellenreuther from the firm due to his illness, followed by the resignation of a group of SAP employees who were working together with Wellenreuther in SAP as a firm within a firm [32], and Wellenreuther establishing DCW (Dr. Claus Wellenreuther GmbH \& Co. KG) after the recovery from his illness in 1983-as a software firm, developing similar software programs to that of SAP for the small and medium enterprises, which have been later on taken over by SAP [61]. Hence, the splitting of the counterfactual hybrid SAP into a consulting and a software firm independent from each other can be seen as a counterfactual which is an alternative factual that occurred in consecutive time. Even though the remaining cofounders did not change the structure of SAP to a consulting firm, after the resignation of Wellenreuther, and the introduction of new versions of $R$, consultants were required for the installation of the software program [32] — which implies that at a certain point consulting and software development started to cooperate to generate a value for customers. Until today, the ERP market is recognized by this phenomenon [62]. The installation itself is not as cost intensive as the customization of the ERP software programs according to the specific needs of customers. 


\subsection{The Prograde Degree of Causality}

Figure 1 visualizes the factual and the counterfactual events over time, as it has been described in Section 3. Here, the abscissa corresponds to the time axis, whereas the ordinate axis corresponds to the space of all admissible states as described by Lehmann-Waffenschmidt [31]. The author asks whether the successful market shaping follows straightforward from the product innovation, i.e., is the new technological knowledge (initially in tacit form) a necessary, a strong, or a weak consequence of the successful market shaping? In order to answer this question, the prograde degree of causality is a useful tool [31]. Based on the definition of Lehmann-Waffenschmidt [31] as explained in Section 3, the author counts the number of all connecting paths between the event of SAP cofounders developing the software program $\left(\mathrm{E}_{\mathrm{i}}\right)$ and the event of successful market shaping $\left(\mathrm{E}_{\mathrm{i}+7}, \mathrm{E}^{\mathrm{I}, \mathrm{VII}}{ }_{i+7}\right)$, and puts this into relation with the number of all alternatively possible paths between the event $E_{i}$ and any event at the time $\mathrm{i}+7$. Formally, this is given as $C^{\mathrm{P}}{ }_{\mathrm{Ei}->\mathrm{Ei}+7, \mathrm{E}^{\mathrm{I}, \mathrm{VII}} \mathrm{i+7}}=3 / 9=0.33$, which shows a weak causality. On the other hand, the event of no successful market shaping $\left(\mathrm{E}^{\mathrm{II}, \mathrm{II}, \mathrm{V}, \mathrm{VI}, \mathrm{VIII}, \mathrm{IX}}{ }_{i+7}\right)$ appears to be stronger in causality than the event of the successful market shaping, $\mathrm{C}^{\mathrm{P}}{ }_{\mathrm{Ei}->\mathrm{E}}^{\mathrm{II}, \mathrm{II}, \mathrm{V}, \mathrm{VI}, \mathrm{VIII}, \mathrm{IX}}{ }_{i+7}=6 / 9=0.67$. These numbers can be interpreted in terms of their closeness to 0 or 1, indicating two extreme cases of "no consequence" and "necessary consequence", respectively. Hence, it can be seen that even though the successful market shaping followed the product innovation later in time, it is not a necessary consequence of the product innovation.

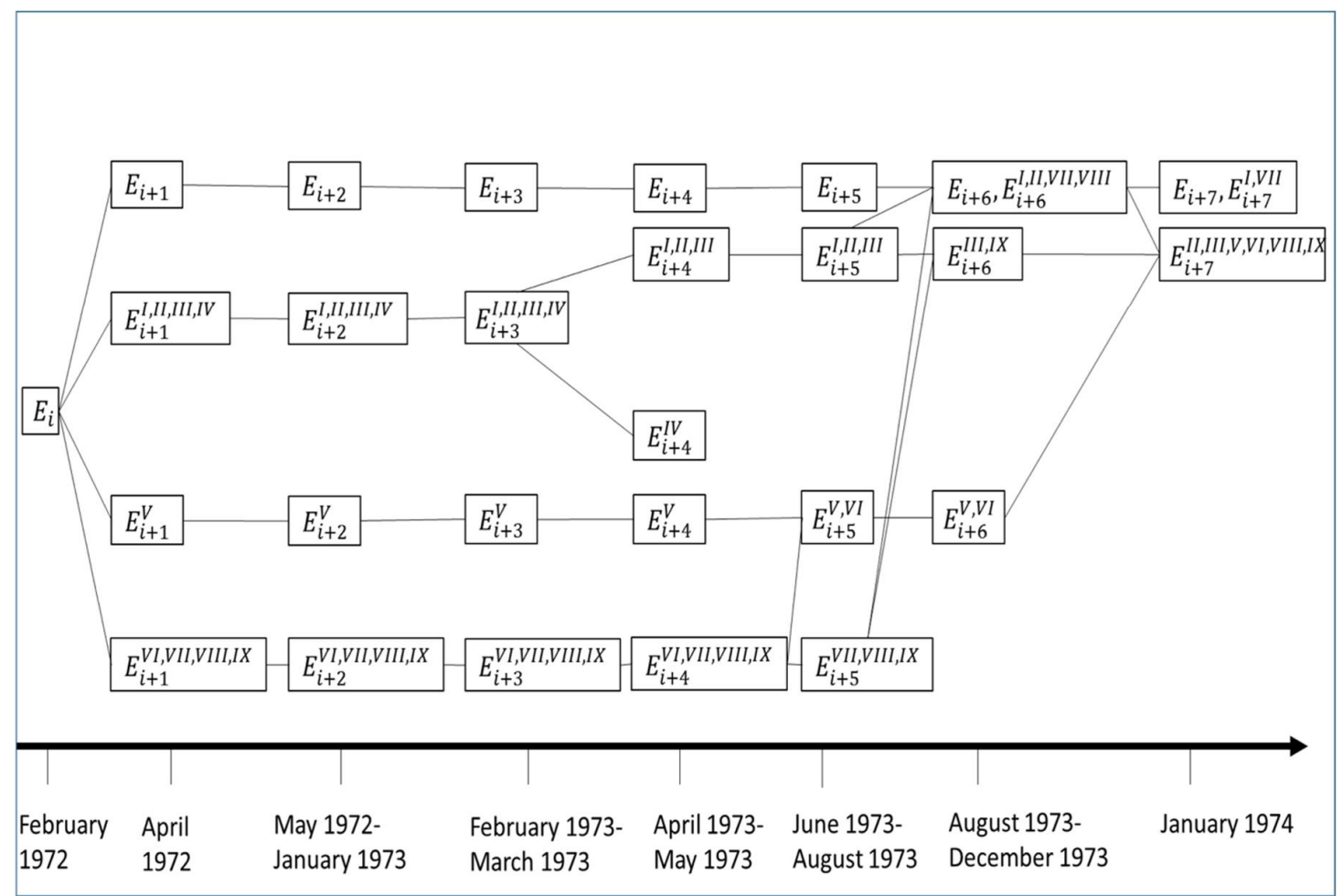

Figure 1. Contingency graph. Source: own illustration of the author.

This contingent nature of the market emergence [6] is also reflected in the long-lasting debate over adaptability versus standardization in case of the ERP market [40]. With respect to the market context as it was described in 4.1, the author concludes that the emergence and the diffusion of an integrated business software in real time did not necessarily need to occur in case of SAP. By using the widely accepted definition of a contingent event as an event which is "not impossible but not necessary" [31], the results from the counterfactual study and the prograde degree of causality point out to the contingent nature of a market. In a previous study, it has been observed that SAP's product innovation 
shaped the market by three different effects on transaction costs, network externalities and agency costs [33] but this was by no means a necessary consequence of the product innovation, since subjective knowledge can take on different forms as the generators of this subjective knowledge frame the market by means of different business conceptions, with which an idea becomes institutionalized.

\section{Concluding Remarks}

Prior to proceeding with concluding remarks, some limitations need to be addressed. A question that arises is according to which criteria the points of time were selected. Since the approach proposed by Lehmann-Waffenschmidt [31] only describes how the graph theoretical model can function, it is the duty of the model builder to find the relevant events corresponding to the points of time. The graph theoretical approach is not ignorant on the choice of the relevant events; it points out that these events can be either generated by the system itself, or by decision makers, and can either occur simultaneously or sequentially, hence giving a guidance for application in different contexts. Since for the context of the author a number of contributions exist, these were the sources used for classifying and identifying key events and counterfactual scenarios in building the model. In this sense, the historical context and the previous research results were relevant. The ongoing research points out the historical path of the product innovation and market shaping practices of SAP by giving the factors of influence that contributed to the success of SAP.

A second concern can be the presumption that by increasing the number of alternatively possible time paths the prograde degree of causality can be minimized to zero, or by decreasing the number of alternatively possible time paths this degree can be maximized to one. This concern can be answered by the fact that the operationalization of the contingency approach does not involve the creation of new realities, but it rather observes the coevolution of different alternatives over historical time, hence, using these different evolutions as alternatively possible time paths. According to the theoretical conception by Lehmann-Waffenschmidt [31], there are different patterns that can emerge as a result of the model. Whereas the model presented by the author shows a multifurcation without later convergence (hence, a slight transformation of the structural pattern 1 in Lehmann-Waffenschmidt [31]), theoretically it is possible that a bifurcation or a multifurcation ends up in a convergence, corresponding to the structural pattern 2 in Lehmann-Waffenschmidt [31], where he gives the example of the convergence hypothesis in neoclassical growth theory.

A third issue that can be pointed out is that the events were not "equidistant" in the historical sense. Here, the author points out to the nature of the irreversible historical time, which is different than e.g., a well-defined sequential game from noncooperative game theory in the sense that historical events that can be decisive in the evolution of a market or a market segment do not usually occur in equidistant points of time due to their open-loop evolving character.

Finally, it must be mentioned that the model takes the assumption of equal probabilities for the alternatively evolving processes. Even though Lehmann-Waffenschmidt's [31] approach allows to integrate probabilities in the framework of analysis, the question is how to determine probabilities, once singular processes in a very specific historical context are observed, which do not allow the translation of the context into a probabilistic experiment [31]. Hence, the only possibility to integrate any probability weights remains as introducing these subjectively, which does not seem to be a plausible approach due to its arbitrariness.

By keeping these concerns in mind, the author concludes his research as follows: By questioning the causal relationship between product innovation and market shaping, it was found out that the pioneer market creation phase of product innovations is associated with uncertainty in form of contingent events that may lead to the failure of a product innovation and the successful market shaping. A product innovation is actually relevant for matching needs to technology [63], but is considered as risky and having a low probability of survival [64]. Hence, the uncertain phase of market evolution and the expansion of the pioneer firm to the market has a contingent character (between chance and necessity). This is in line with Potts' [65] observation that innovations 
may be observed as special types of spontaneous orders in terms of their unpredictability. Once innovations are observed as spontaneous orders, they can either be called as historically singularities and can be explored systematically-theoretically, or they can be modelled stochastically and can be explored by using stochastic methodology [31]. Nevertheless, both concepts lack an understanding of the search for recurring patterns or structural similarities, which can be addressed by Lehmann-Waffenschmidt's $[20,31]$ approach. Hence, this methodological innovation enables to measure the relationship between product innovation and market shaping in a gradual way, and can be used to explore the question of whether the market success has been a necessary, a strong, or a weak consequence of the product innovation. This way of a gradual measurement of causality regarding the relation between product innovation and market shaping is an innovative step to evaluate economic change and pioneer market creation from an evolutionary point of view, especially by updating the basic variation-selection-retention scheme with a Lamarckian perspective, and framing the process of product innovation and market-shaping from a monistic ontological viewpoint [37] by providing the necessary link between change in nature and change in economy through the theory of mind of Hayek [26]. As it was found out by calculating the prograde degree of causality, the relation between new technological knowledge (such as a product innovation) and the successful market shaping (the market success of this product innovation) does not have to be a necessity relation. Events involved in the evolutionary phases of the perception of information, the generation of new knowledge, the capabilities for generating a business conception and the emergence of observable artefacts often involve more than one possible alternative, out of which a realization occurs. New technological knowledge that can address a market gap and can provide the solution to a problem does not necessarily need to end in the successful creation of a new market segment, where new technological knowledge that is relevant for the market to address a gap does not necessarily end in the successful creation of a new market segment. Hence, the analysis shows that even though product innovation and market success of that product occur as sequential events over time, the market success is not a necessary consequence of the product innovation. Without the analysis and by focusing on the universal Darwinism approach, the consequence would be to observe these two events in a necessity relation and therefore to fall into the trap of post hoc ergo propter hoc. In case of the ERP market, the market emergence was not a necessary consequence of SAP's product innovation, and the counterfactual study suggests that if the market success of SAP's product innovation were not the case, the market for business software would have continued with the dominance of single-function software programs-a notion that is quite the opposite of what ERP is aimed at.

The findings are relevant for a number of reasons. First of all, the author challenges evolutionary economics by pointing out to the shortcomings of the universal Darwinian approach for explaining market evolution, and the shortcomings of neo-Schumpeterian evolutionary economics of failing to integrate marketing knowledge into the framework of analysis, as well as that of Schumpeter's heroic figure of entrepreneur. In the sense of Buenstorf [49] and Erkut [6], these findings may help for understanding how the perceptions of economic actors evolve over time and shape a new market segment by means of their business conceptions and their practices. Second, the author uses a quantitative approach that operationalizes the idea of innovation as a spontaneous order into a graph theoretical context in order to analyze causality relations, especially under the consideration of business conceptions that are neglected by the neo-Schumpeterian framework of analysis [28,29]. By providing an analytical model of innovation as a spontaneous order, the author contributes to the stream of research on spontaneous orders by a formalized approach. Especially the use of graph theory to analyze causality relations has been on the agenda of evolutionary economics since a couple of decades [30] and the contribution by Lehmann-Waffenschmidt [31] is an important milestone in providing a theoretical framework, but hitherto there was a gap to use this formalized framework in a specific market context, which has been achieved by the author. Third, the study also has an implication for managerial economics by pointing out to deviate from the image of a "heroic individual 
innovator" [35], which does not say much about the evolution of technologies and markets, since the image of a predefined success story is far from the reality.

Nevertheless, the latter point has been neglected by both convenient textbook economics and the framework of the universal Darwinian and Schumpeterian approaches in evolutionary economics, easily falling into the trap of post hoc ergo propter hoc [31]. The counterfactual analysis of the author aims to contribute to a better understanding of the historical evolution of the ERP market by introducing the concept of contingency and the introduction of non-realized alternative and plausible developments. Through this way, not only was it observable that the emergence of the ERP market was not predetermined, but it has also been identified that the transformation of (objective) information to (subjective) knowledge has different alternatively possible paths, which would have different developments and implications for market shaping and market evolution. It is this subjective and tacit dimension of knowledge that opens the way for a number of possibilities, with which economic actors are able to build competitive advantages and contribute to the market evolution with the practices based on their own subjective knowledge. By shifting the focus from the heroic image of the entrepreneur and the product innovation as a success story to the contingent nature of knowledge generation based on the conditions of the market, the technology and the entrepreneurial inputs, both economics and management science can shed light on understanding, shaping and explaining market processes from a complex angle. This observation can serve as a recognized pattern of the historical case study with respect to the future of these disciplines and future innovations that will bring the market evolution forward.

Acknowledgments: I would like to thank Marco Lehmann-Waffenschmidt from TU Dresden and the participants of the symposium on W. G. Waffenschmidt at the University of Heidelberg as well as two anonymous referees for helpful comments and suggestions. I acknowledge support by the Open Access Publication Funds of the SLUB/TU Dresden.

Conflicts of Interest: The author declares no conflicts of interest.

\section{Abbreviations}



\section{References}

1. Lehmann-Waffenschmidt, M. Strukturähnlichkeiten und -ungleichheiten evolvierender Ökonomien. Wiss. Z. Tech. Univ. Dresd. 2008, 57, 105-109.

2. Erkut, B. Entrepreneurship and Economic Freedom-Do Objective and Subjective Data Reflect the Same Tendencies? Entrep. Bus. Econ. Rev. 2016, 4, 11-26. [CrossRef]

3. Zygmunt, J. Entrepreneurial Activity Drivers in the Transition Economies. Evidence from the Visegrad Countries. Equilib. Q. J. Econ. Econ. Policy 2018, 13, 89-103. [CrossRef]

4. Araujo, L.; Finch, J.; Kjellberg, H. Reconnecting Marketing to Markets: An Introduction. In Reconnecting Marketing to Markets; Araujo, L., Finch, J., Kjellberg, H., Eds.; Oxford University Press: Oxford, UK, 2010; pp. 1-10.

5. Jaworski, B.; Kohli, A.K.; Sahay, A. Market-Driven versus Driving Markets. J. Acad. Mark. Sci. 2000, 28, 45-54. [CrossRef]

6. Erkut, B. Product Innovation and Market Shaping: Bridging the Gap with Cognitive Evolutionary Economics. Indraprastha J. Manag. 2016, 4, 3-24. 
7. Hayek, F.A. Law, Legislation and Liberty: A New Statement of the Liberal Principles of Justice and Political Economy; Routledge: London, UK, 1982.

8. Koslowski, P. Principles of Ethical Economy; Kluwer Academic: Dordrecht, The Netherlands, 2001.

9. Butos, W.N. Entrepreneurship and the Generation of Knowledge. In Austrian Economics and Entrepreneurial Studies; Koppl, R., Birner, J., Kurrild-Klitgaard, P., Eds.; Emerald: Bingley, UK, 2003; pp. 97-112.

10. Erkut, B.; Kaya, T.; Lehmann-Waffenschmidt, M.; Mahendru, M.; Sharma, G.D.; Srivastava, A.; Srivastava, M. A Fresh Look on Financial Decision-Making from the Plasticity Perspective. Int. J. Ethics Syst. 2018, in press.

11. Witt, U. Competition as an Ambiguous Discovery Procedure: A Reappraisal of F. A. Hayek's Epistemic Liberalism. Econ. Philos. 2013, 29, 121-138. [CrossRef]

12. Kjellberg, H.; Storbacka, K.; Akaka, M.; Chandler, J.; Finch, J.; Lindemann, S.; Löbler, H.; Mason, K.; McColl-Kennedy, J.; Nenonen, S. Market Futures/Future Markets: Research Directions in the Study of Markets. Mark. Theory 2012, 12, 219-223. [CrossRef]

13. Witt, U. The Future of Evolutionary Economics: Why The Modalities of Explanation Matter. J. Inst. Econ. 2014, 10, 645-664. [CrossRef]

14. Nelson, R.R.; Winter, S.G. An Evolutionary Theory of Economic Change; Belknap Press/Harvard University Press: Cambridge, MA, USA, 1982.

15. Hodgson, G.M. Agency, Institutions, and Darwinism in Evolutionary Economic Geography. Econ. Geogr. 2009, 85, 167-173. [CrossRef]

16. Levit, G.S.; Hossfeld, U.; Witt, U. Can Darwinism be “Generalized" and of What Use Would This Be? J. Evolut. Econ. 2011, 21, 545-562. [CrossRef]

17. Foxall, G.R.; Fawn, J.R. An Evolutionary Model of Technological Innovation as a Strategic Process. Technovation 1992, 12, 191-202. [CrossRef]

18. Lehmann-Waffenschmidt, M. Gibt es eine Evolution in der Wirtschaft? Zur Diagnose und komparativ-evolutorischen Analyse des wirtschaftlichen Wandels. In Neue Konzepte der Ökonomik—Unternehmen zwischen Nachhaltigkeit, Kultur und Ethik; Antoni-Komar, I., Beermann, M., Lautermann, C., Müller, J., Paech, N., Müller, H., Schneidewind, U., Schulz, R., Eds.; Metropolis: Marburg, Germany, 2009; pp. 369-396.

19. Hodgson, G.M. Is Social Evolution Lamarckian or Darwinian? In Darwinism and Evolutionary Economics; Laurent, J., Nightingale, J., Eds.; Edward Elgar: Cheltenham, UK, 2001; pp. 87-118.

20. Lehmann-Waffenschmidt, M. Der kontingenztheoretische Ansatz zur Strukturanalyse verlaufs- und ergebnisoffener wirtschaftlicher Prozesse. Wiss. Z. Tech. Univ. Dresd. 2004, 53, 131-136.

21. Miller, D. A Downside to the Entrepreneurial Personality? Entrep. Theory Pract. 2015, 39, 1-8. [CrossRef]

22. Christensen, C.M. The Innovator's Dilemma. When New Technologies Cause Great Firms to Fail; Harvard Business School Publishing: Boston, MA, USA, 2016.

23. Buenstorf, G. How Useful is Generalized Darwinism as a Framework to Study Competition and Industrial Evolution? J. Evolut. Econ. 2005, 16, 511-527. [CrossRef]

24. Koen, P.; Ajamian, G.; Burkart, R.; Clamen, A.; Davidson, J.; D'Amore, R.; Elkins, C.; Herald, K.; Incorvia, M.; Johnson, A.; et al. Providing Clarity and A Common Language to The "Fuzzy Front End". Res. Technol. Manag. 2001, 44, 46-55. [CrossRef]

25. Rizzello, S.; Spada, A. The Oversight of Behavioral Economics on Hayek's Insights. In Hayek and Behavioral Economics; Frantz, R., Leeson, R., Eds.; Palgrave Macmillan: Hampshire, UK, 2013; pp. 301-312.

26. Hayek, F.A. The Sensory Order: An Inquiry into the Foundations of Theoretical Psychology; The University of Chicago Press: Chicago, IL, USA, 1952.

27. Fuster, J.M. Hayek in Today's Cognitive Neuroscience. In Hayek in Mind: Hayek's Philosophical Psychology; Marsh, L., Ed.; Emerald: Bingley, UK, 2011; pp. 3-11.

28. Witt, U. Imagination and Leadership-The Neglected Dimension of an Evolutionary Theory of the Firm. J. Econ. Behav. Organ. 1998, 35, 161-177. [CrossRef]

29. Witt, U. Firms as Realizations of Entrepreneurial Visions. J. Manag. Stud. 2007, 44, 1125-1140. [CrossRef]

30. Santarelli, E. Directed Graph Theory and the Economic Analysis of Innovation. Metroeconomica 1995, 46, 111-126. [CrossRef]

31. Lehmann-Waffenschmidt, M. Contingency and Causality in Economic Processes-Conceptualizations, Formalizations and Applications in Counterfactual Analysis. Eur. Rev. 2010, 18, 481-505. [CrossRef]

32. Meissner, G. SAP_Die Heimliche Softwaremacht; Hoffmann und Campe: Hamburg, Germany, 1997.

33. Erkut, B. What did SAP change? A Market Shaping Analysis. Mark. Brand. Res. 2018, 5, 51-63. 
34. Yun, J.J.; Won, D.; Jeong, E.; Park, K.; Yang, J.; Park, J. The Relationship between Technology, Business Model, and Market in Autonomous Car and Intelligent Robot Industries. Technol. Forecast. Soc. Chang. 2016, 103, 142-155. [CrossRef]

35. Tuomi, I. Networks of Innovation: Change and Meaning in the Age of the Internet; Oxford University Press: Oxford, UK, 2002.

36. Witt, U. Market Opportunity and the Organizational Grind-The Two Sides of Entrepreneurship. In Advances in Austrian Economics-Austrian Economics and Entrepreneurial Studies; Koppl, R., Birner, J., Kurrild-Klitgaard, P., Eds.; JAI Press: New York, NY, USA, 2003; pp. 131-151.

37. Witt, U. What is Specific about Evolutionary Economics? J. Evolut. Econ. 2008, 18, 547-575. [CrossRef]

38. Festre, A.; Garrouste, P. Hayek on Expectations: The Interplay between Two Complex Systems; University of Nice Sophia Antipolis: Nice, France, 2016.

39. Nambisan, S. Software Firm Evolution and Innovation-Orientation. J. Eng. Technol. Manag. 2002, 19, 141-165. [CrossRef]

40. Lehrer, M.; Behnam, M. Modularity vs Programmability in Design of International Products: Beyond the Standardization-Adaptation Tradeoff? Eur. Manag. J. 2009, 27, 281-292. [CrossRef]

41. Leimbach, T. Die Geschichte der Softwarebranche in Deutschland, Entwicklung und Anwendung von Informations—und Kommunikationstechnologie Zwischen den 1950ern und heute; Universitätsbibliothek München: Munich, Germany, 2010.

42. Müller, T. SAP im Mikropolis-Modell-Analyse des SAP-Technikentwicklungspfades auf der Grundlage sozialwissenschaftlicher Techniktheorien und des Mikropolis-Modells; University of Hamburg: Hamburg, Germany, 2010.

43. Antero, M.C. A Multi-Case Analysis of the Development of Enterprise Resource Planning Systems (ERP) Business Practices; LIMAC: Copenhagen, Denmark, 2015.

44. Von Hippel, E. Lead Users: A Source of Novel Product Concepts. Manag. Sci. 1986, 32, 791-805. [CrossRef]

45. Campbell-Kelly, M. From Airline Reservations to Sonic the Hedgehog: A History of the Software Industry; MIT Press: New Baskerville, MA, USA, 2003.

46. Buenstorf, G. Schumpeterian Incumbents and Industry Evolution. J. Evolut. Econ. 2016, 26, 823-836. [CrossRef]

47. Powell, A. Apple: An Alternative Approach to Business. 2015. Available online: http:/ /www.adampowell. com/textexhibit/apple.pdf (accessed on 1 October 2017).

48. Buenstorf, G. Opportunity Spin-Offs and Necessity Spin-Offs. Int. J. Entrep. Ventur. 2009, 1, 22-40. [CrossRef]

49. Buenstorf, G. Creation and Pursuit of Entrepreneurial Opportunities: An Evolutionary Economics Perspective. Small Bus. Econ. 2007, 28, 323-337. [CrossRef]

50. Henkel, H.O. Die Macht der Freiheit; Econ: Berlin, Germany, 2001.

51. Davies, A.; Frederiksen, L. Project-Based Innovation: The World after Woodward. In Technology and Organization: Essays in Honour of Joan Woodward; Phillips, N., Sewell, G., Griffiths, D., Eds.; Emerald: Bingley, UK, 2010; pp. 177-216.

52. Computerwoche. Dietmar Hopp Wird 75. 2015. Available online: http://www.computerwoche.de/a/ dietmar-hopp-wird-75,3097923 (accessed on 27 July 2017).

53. Grad, B. A Personal Recollection: IBM's Unbundling of Software and Services. IEEE Ann. Hist. Comput. 2002, 24, 64-71. [CrossRef]

54. Audretsch, D.B.; Link, A.N. Entrepreneurship and Innovation: Public Policy Frameworks. J. Technol. Transf. 2012, 37, 1-17. [CrossRef]

55. Software AG (n.n., Darmstadt, Germany). Unternehmensgeschichte. Available online: http://www. softwareag.com/de/company/companyinfo/history/default.asp (accessed on 1 October 2017).

56. Thürmer, T. War die Krise alternativlos? Eine kontrafaktische Analyse der Firmengeschichte von IBM; TU Dresden: Dresden, Germany, 2013.

57. Levy, H.M. Capability-Based Computer Systems; Digital Press: Bedford, UK, 1984.

58. Plattner, H.; Scheer, A.-W.; Wendt, S.; Morrow, D.S. Dem Wandel voraus: Hasso Plattner im Gespräch; Galileo: Bonn, Germany, 2000.

59. Neumann, C.; Srinivasan, J. Managing Innovation from the Land of Ideas and Talent: The 10-Year Story of SAP Labs India; Springer: Berlin/Heidelberg, Germany, 2009. 
60. Blasgen, M.; Traiger, I.; Putzolu, F.; Mohan, C.; Chamberlin, D.; Lindsay, B.; Wade, B.; Selinger, P.; Selinger, B.; Gray, J.; et al. The 1995 SQL Reunion: People, Projects, and Politics. 20 August 1997. Available online: http:/ / www.mcjones.org/System_R/SQL_Reunion_95/SRC-1997-018.pdf (accessed on 16 June 2018).

61. Schüler, H.-P. SAP Kauft Anbieter von Branchenlösungen. 2003. Available online: https://www.heise.de/ newsticker/meldung/SAP-kauft-Anbieter-von-Branchenloesungen-83091.html (accessed on 23 October 2017).

62. Scheer, A.-W.; Habermann, F. Making ERP a Success. Commun. ACM 2000, 43, 57-61. [CrossRef]

63. Teubal, M.; Zuscovitch, E. Evolutionary Product Differentiation and Market Creation in Turbulent Economic Environments. Econ. Innov. New Technol. 1997, 4, 265-286. [CrossRef]

64. Colombelli, A.; Krafft, J.; Vivarelli, M. To Be Born is Not Enough: The Key Role of Innovative Start-Ups. Small Bus. Econ. 2016, 47, 277-291. [CrossRef]

65. Potts, J. Innovation is a spontaneous order. Cosmos Taxis 2014, 2, 1-10.

(C) 2018 by the author. Licensee MDPI, Basel, Switzerland. This article is an open access article distributed under the terms and conditions of the Creative Commons Attribution (CC BY) license (http://creativecommons.org/licenses/by/4.0/). 